\title{
FORMAÇÃO DO PROFESSOR-EDUCADOR MATEMÁTICO EM CURSOS DE LICENCIATURA
}

\section{Formation de l'enseignant/éducateur des mathématiques dans les cours de Licence en Mathématiques}

Zélia Milléo Pavão ${ }^{1}$

\section{Resumo}

Este artigo apresenta apontamentos para a formação do professor-educador matemático em cursos de Licenciatura em Matemática. Trata-se de um estudo que subsidia questões gerais sobre a formação de professores de Matemática, segundo um modelo reflexivo e que podem servir para um novo pensar de cursos de formação de professores. Da investigação, destacam-se alguns aspectos fundamentais para a formação do professor-educador matemático: a definição do verdadeiro papel das Licenciaturas; o curso como um momento propício para o repensar de concepções dos futuros professores; a composição das disciplinas do curso de modo que a relação teoria-prática se configure como eixo central nos programas; a formação do professor em Educação Matemática; a universidade entendida como espaço de produção de saberes e de experiências significativas de aprendizagem e comprometida com a formação continuada dos professores.

Palavras-chave: Formação de Professores; Licenciatura em Matemática, Educação Matemática.

Professora e Pesquisadora do Programa de Pós-Graduação em Educação da PUCPR.

E-mail: zelia.milleo@pucpr.br 


\section{Rèsumé}

Cet article présente des renseignements au sujet de la formation de l'enseignant/ éducateur des mathématiques dans les cours de Licence en Mathématiques. Il s'agit d'une étude qu'offre de base théoriques aux questions générales sur la formation d'enseignants en mathématiques selon le modèle refléxif et que peuvent servir comme une nouvelle façon de penser les cours de formation d'enseignants. De cette recherche sont isuus des aspects fondamentaux pour la formation de l'enseignant/éducateur en mathématiques : la définition de ce qu'est le vrai rôle des Licences ; le cours en tant qu'un moment favorable pour re-penser les conceptions des futures enseignants ; la composition des disciplines du cours de façon que le rapport entre théorie et pratique se montre comme l'axe central dans les programmes ; la formation de l'enseignant de l'education mathématique ; l'université comprise comme un espace de production des savoirs et d'expériences significatives d'apprentissage et engagée dans la formation continue des enseignants.

Mots-clés: Formation d'enseignants ; Licence en mathématiques, Education Mathématique .

Em nenhum momento como nos dias de hoje, tem se discutido tão amplamente a formação de professores em todos os níveis e, especialmente, a formação dos que se dedicam ao ensino fundamental e médio. A questão da formação de professores vem caracterizando, já há alguns anos, uma preocupação fundamental na comunidade educacional a denotar-se pelos inúmeros documentos e estudos citados por Ribeiro (1999) e publicados em âmbito mundial.

De acordo com Saul (1996), as práticas de formação de professores têm sido construídas segundo a lógica da racionalidade técnica, ou seja, o professor como técnico que aplica com rigor as regras que derivam do conhecimento científico. Nessa tradição de formação de professores, o que tem se verificado no âmbito educacional é um profundo afastamento entre o conhecimento científico e o mundo da prática. Nos cursos de formação de professores, o problema maior concentra-se no distanciamento entre a teoria e a prática.

Por tratar-se de um modelo no qual as atividades são entendidas como aplicações rigorosas do conhecimento científico, decorre que, nos cursos de formação, a prática é deixada para o final do curso, quando se supõe que o futuro professor já tenha adquirido todos os conhecimentos necessários para aplicar em sala de aula (RIBEIRO, 1999, p. 30).

Dessa tendência, provém a idéia da prática como um momento de aplicação de regras e técnicas desenvolvidas teoricamente.

Repensar a formação de professores, na busca da superação de um modelo técnico, conduzindo à implantação de uma proposta de formação do 
professor segundo um modelo reflexivo é uma das questões centrais na problemática formação de professores (PÉREZ GÓMEZ, 1995). O estabelecimento de uma proposta de formação do professor reflexivo supõe uma formação centrada na prática, sendo esta entendida como um processo de investigação e articulação permanente na relação com a teoria e ocupando o eixo central do currículo dos cursos de formação de professores. Uma proposta de formação com ênfase na prática não trata de abandonar o conhecimento teórico, pelo contrário, como bem ressalta Perrenoud (1993), não se dispensa de forma alguma uma sólida formação teórica, mas entende-se que "esta só tem interesse se se articular com a prática em situação" (p. 149), ou seja, a relação teoria-prática deve ser entendida numa relação dialética, que promova a açãoreflexão do professor também numa relação dialética permanente, como um sistema em cadeia. Esse movimento pretende transpor a formação do professor como mero transmissor de conhecimento para a formação do professor que constrói/reconstrói o conhecimento num processo investigativo.

Em se tratando da formação de professores de Matemática, como destaca Ribeiro (1999), cada uma das formas de conceber e tratar um conhecimento matemático resulta da visão que o professor tem da matemática, de como ele acredita que ocorre o processo de aprendizagem e dos objetivos que atribui ao ensino de matemática, ou seja, depende das concepções do professor que são formadas durante todo o período escolar e que podem permanecer inalteradas, caso os cursos de Licenciatura não atendam à sua finalidade de formação do professor reflexivo. Segundo Perrenoud (1993), "alguns formadores universitários contribuem, ainda hoje, para formar professores sem terem qualquer outra experiência da sala de aula a não ser o seu passado como alunos" (p. 147).

Para uma nova visão da formação do professor na Licenciatura é essencial definir o papel da Prática de Ensino e do Estágio, que de acordo com a Lei de Diretrizes e Bases da Educação Nacional (LDB n 9394/96), devem compor o currículo desde o início do curso.

A relação permanente teoria-prática na formação dos professores implica numa articulação das disciplinas que compõem o curso de Licenciatura, o que supõe articular três componentes básicos no rol das disciplinas de formação do professor nos cursos de Licenciatura em Matemática: conhecimentos em conteúdos específicos, conhecimentos de formação pedagógica e conhecimentos em Educação Matemática, como sugerem Bertoni (1995) e Wagner, Nasser e Tinoco (1997). A formação inicial do professor em Educação Matemática, até então relegada aos cursos de pós-graduação, passa a desempenhar uma dimensão-chave na articulação entre conhecimentos específicos e formação pedagógica. No entanto, a maioria dos cursos de Licenciatura ainda não inclui disciplinas de formação em Educação Matemática. Algumas 
propostas já estão sendo desenvolvidas e difundidas por pesquisadores (FAINGUELERNT, PEREZ; MOURA, 1995; WAGNER, NASSER; TINOCO, 1997), porém grande parte das Licenciaturas permanece estruturada apenas em dois blocos de conhecimentos: específicos e pedagógicos.

De acordo com Fiorentini (1998), a prática pedagógica concebida a partir do trabalho investigativo-reflexivo do professor sobre o próprio trabalho é a melhor maneira de promover a formação e o desenvolvimento profissional dele. Pesquisas desenvolvidas questionam se as idéias transmitidas nas Licenciaturas por meio de exposições e leituras são assimiladas pelos licenciandos, afirmando que estes não mudam sua prática só pela exposição a métodos e a teorias de Educação Matemática (BERTONI, 1995). Essas pesquisas levam à constatação de que é preciso envolver os licenciandos em atividades que os façam questionar a própria ação docente desde o início da formação, ao contrário do que acontece atualmente na Licenciatura, onde a formação para a docência é deixada para o final do curso, sendo que a experiência docente, propriamente dita, é vivenciada na fase terminal da graduação. Comenta Beatriz D’Ambrósio (1993) que “futuros professores constroem seu conhecimento sobre o ensino da Matemática através de suas experiências com o ensino" (p. 39). Assim, denota-se a importância de uma iniciação à investigação na formação de base dos professores, por considerar-se que a investigação induz a uma relação com os saberes (PERRENOUD, 1993).

Como elo entre teoria e prática na formação e desenvolvimento profissional do professor de Matemática tem-se a pesquisa como atitude cotidiana, buscando na prática o repensar da teoria e na teoria o repensar da prática (D’AMBRÓSIO, 1996). A prática, ocupando uma posição de destaque na formação dos professores e entendida como um processo de investigação e diálogo com a realidade, deve promover um movimento de ação e reflexão contínua sobre a ação docente, ou seja, a reflexão sobre a ação vai gerar uma nova ação, que vai gerar uma nova reflexão e assim por diante, sucessivamente. O movimento descrito: "conhecimento na ação, reflexão na ação e reflexão sobre a ação e sobre a reflexão na ação" é sugerido por Schön (1995) para a "formação de professores como profissionais reflexivos".

Baseando-se na concepção exposta, entende-se que o professor aprende fazendo e refletindo "na e sobre a ação". Sendo assim, é essencial que se desenvolva no professor a habilidade de saber aprender, aprender sempre e, sobretudo, aprender a maneira pela qual seus alunos aprendem, extinguindo a idéia de que o trabalho do professor consiste apenas em repassar informações e conhecimentos acumulados pelo ser humano, considerando que, "O professor não é quem dá aula, mas quem sabe fazer o aluno aprender, do que decorre que deve, mais que todos, saber aprender" (DEMO, 1998, p. 45). 
É fundamental ao futuro professor que, concluída a Licenciatura e inserido no mercado de trabalho, no caso, ao trabalho com a docência, dê continuidade à atitude de reflexão permanente sobre a prática. Para isso, é necessário que se estabeleçam condições e espaço para a discussão e crítica coletiva de saberes dos professores, trocas de experiências e de discussão de dificuldades encontradas no processo educativo dentro dos estabelecimentos de ensino. A formação continuada dos professores deve constituir-se em um esforço pessoal de cada professor, como sujeito responsável pela ação docente e coletivo, como componente de um grupo com objetivos educacionais comuns. Os projetos pedagógicos dos estabelecimentos de ensino devem contemplar a formação continuada de seus professores, promovendo a construção de novos saberes profissionais. A essência da formação continuada é a reflexão crítica sobre a própria prática no sentido da transformação do professor (PAVÃO, 1999).

Salienta-se que a formação continuada não deve ser confundida com momentos isolados de "capacitação docente" por meio de cursos esporádicos, nos quais o professor é simples ouvinte. Há necessidade de se investir em uma formação continuada do professor, na qual haja espaço para o diálogo, exposição de dificuldades encontradas, reflexão coletiva e elaboração de novas possibilidades para o trabalho docente. Num sentido mais amplo da formação continuada, alguns autores já apontam em direção ao uma formação permanente dos professores, que contemple "retornos periódicos à universidade durante toda a vida profissional" (D’AMBRÓSIO, 1996, p. 97).

\section{Alguns apontamentos}

Até o momento, algumas questões sobre a formação do professoreducador matemático em cursos de Licenciatura puderam ser configuradas. Tais questões não encerram a discussão acerca da formação desses profissionais, porém representam apontamentos e considerações construídas a partir de pesquisa desenvolvida durante o curso de Mestrado em Educação da Pontifícia Universidade Católica do Paraná. Tratam-se de apontamentos "provisórios", no sentido de provisoriedade do saber, um saber que se encontra em constante construção e evolução num processo de reflexão crítica permanente. A seguir, a retomada de alguns aspectos fundamentais para a formação do professor-educador matemático em cursos de Licenciatura são destacados.

Ressalta-se a importância de se definir o verdadeiro objetivo dos cursos de Licenciatura em Matemática. Ao terminar o curso, o professor recebe um diploma que lhe confere a habilitação de Licenciado em Matemática. No entanto, muitas vezes, as habilidades e competências adquiridas durante todo 
o curso não correspondem à formação esperada. Retoma-se a idéia de que o curso de Licenciatura em Matemática é o momento propício para a construção e o repensar das concepções dos futuros professores de modo que conduzam a uma aprendizagem matemática realmente significativa, sendo a universidade entendida como um espaço de produção de saberes e de experiências significativas de aprendizagem.

Orienta-se para a necessidade do estabelecimento de diretrizes norteadoras dos cursos de Licenciatura, a partir de suportes próprios da Licenciatura, a qual deve primar pela formação do professor que vai atuar, especificamente, no ensino fundamental e médio. Muitas das Instituições de Ensino Superior oferecem, paralelamente, a formação em Bacharelado e Licenciatura. Por conta disso, a ênfase das disciplinas do núcleo comum do curso acaba sendo atribuída à formação do bacharel. A Licenciatura acaba sendo vista como uma ramificação do curso, quando na realidade deveria constituir-se no seu eixo central.

Um outro aspecto bastante significativo refere-se à necessidade de que a formação do professor no curso aconteça no mesmo sentido em que se espera que ele exerça sua profissão, ou seja, o tratamento do futuro professor na Licenciatura deve acontecer no mesmo sentido em que se pretende que ele vá atuar como professor.

Com relação às disciplinas, o curso deve contemplar os seguintes eixos: formação específica em conhecimentos de Matemática, formação pedagógica e formação em Educação Matemática. Acredita-se que as disciplinas que compõem o curso devem acontecer interligadas. Cada uma das áreas de formação deve sustentar e subsidiar a outra, num movimento em que a teoria sirva de elemento orientador e impulsionador da prática e a prática como elemento de investigação da teoria.

A formação do professor de Matemática no curso de Licenciatura deve compreender a formação em Educação Matemática. O curso de Licenciatura é o momento oportuno para o contato inicial do futuro professor de Matemática com questões específicas da área de Educação Matemática, não podendo permanecer relegada aos cursos de pós-graduação, aos quais pouquíssimos professores têm acesso e alguns outros, tardiamente.

O despertar para a importância da formação continuada dos futuros professores na perspectiva do desenvolvimento profissional, num sentido pessoal e coletivo, de modo que desencadeie um processo reflexivo crítico permanente sobre a prática na busca de sua melhoria qualitativa, deve ser compromisso da universidade. Compromisso que deve ser estendido à formação continuada dos professores em serviço por meio de trabalho colaborativo da universidade com a comunidade em que está inserida e das próprias instituições de ensino nas quais os professores atuam. 
Por fim, destaca-se a função dos cursos de Licenciatura em Matemática: promover a formação do professor pesquisador, crítico e reflexivo, por meio da pesquisa investigativa e da elaboração própria do professor sobre suas experiências com o ensino, constituindo-se, dessa maneira, o profissional que constrói os conhecimentos envolvido nas investigações sobre ensino-aprendizagem, produzindo e experimentando novas práticas consonantes aos desafios e expectativas do mundo moderno, de modo a favorecer o processo emancipatório dos alunos e sua formação integral.

\section{Referências}

BERTONI, Nilza. Formação do professor: concepção, tendências verificadas e pontos de reflexão. Temas e Debates, Blumenau, v. 8, n.7, p.8-14, 1995.

D’AMBRÓSIO, Beatriz. Formação de professores de matemática para o século XXI: o grande desafio. Pro-posições, v. 4, n. 1, p. 35-41, mar.1993.

D’AMBRÓSIO, Ubiratan. Educação Matemática: da teoria à prática. Campinas: Papirus, 1996.

DEMO, Pedro. Questões para Teleducação. Petrópolis: Vozes, 1998.

FAINGUELERNT, E. , PEREZ, G., MOURA, M. Formação e atualização do professor de Matemática. In: ENEM, 5., Aracaju,1995. Anais... Aracaju: SbemUFSE, 1995.

FIORENTINI, Dario. O papel da pesquisa e da reflexão no desenvolvimento profissional do professor de Matemática. In: ENEM, 6., São Leopoldo, 1998. Anais... São Leopoldo: Unisinos-Sbem, 1998.

PAVÃO, Zélia Milléo. Avaliação da aprendizagem: concepções e teoria da prática. Curitiba: Champagnat, 1998.

PÉREZ GOMÉZ, Angel. O pensamento prático do professor: a formação do professor como profissional reflexivo. In: NÓVOA, Antonio (org.). Os professores e sua formação. Lisboa: Dom Quixote, 1995.

PERRENOUD, Philippe. Práticas pedagógicas, profissão docente e formação: perspectivas sociológicas. Tradução de Helena Faria et al. Lisboa: Dom Quixote, 1993.

RIBEIRO, Flávia D. A formação do professor-educador matemáticos em cursos de Licenciatura em Matemática. Dissertação (Mestrado em Educação) - PUC-PR, Curitiba,1999. 
SAUL, Ana M. Uma nova lógica para a formação do educador. In: BICUDO, Maria A. V. et al. Formação do educador: dever do Estado, tarefa da Universidade. São Paulo: Ed. UNESP, 1996. v. 1.

SCHÖN, Donald. Formar professores como profissionais reflexivos. In: NÓVOA, Antonio (org.). Os professores e sua formação. Lisboa: Dom Quixote, 1995.

WAGNER, V. P. S., NASSER, L., TINOCO, L. Formação inicial do professor de Matemática. Zetetiké, Campinas, v. 5, n. 7, p.37-51, jan./jun. 1997.

Recebido: 25 de janeiro de 2006 Aprovado: 28 de março de 2006. 